Fixed Point Theory, 21(2020), No. 2, 427-440

DOI: $10.24193 /$ fpt-ro.2020.2.30

http://www.math.ubbcluj.ro/ nodeacj/sfptcj.html

\title{
POSITIVE SOLUTION FOR NONLINEAR FRACTIONAL DIFFERENTIAL EQUATION WITH NONLOCAL MULTI-POINT CONDITION
}

\author{
PIYACHAT BORISUT $*$, POOM KUMAM ${ }^{*, * *, * * * * *}$, IDRIS AHMED*,*** \\ AND KANOKWAN SITTHITHAKERNGKIET $* * * *$
}

${ }^{*}$ KMUTT Fixed Point Research Laboratory, Center of Excellence in Theoretical and Computational Science (TaCS-CoE) and

Department of Mathematics, Faculty of Science, King Mongkut's University of Technology Thonburi (KMUTT), 126 Pracha Uthit Road, Bang Mod, Thrung Khru Bangkok 10140, Thailand E-mail: piyachat.b@hotmail.com

** Department of Medical Research, China Medical University Hospital, China Medical University, Taichung 40402, Taiwan

E-mail: poom.kumam@mail.kmutt.ac.th (Corresponding author)

*** Department of Mathematics and Computer Science, Sule Lamido University, Kafin-Hausa, Jigawa State, Nigeria E-mail: idrisahamedgml1988@gmail.com

****Intelligent and Nonlinear Dynamic Innovations Research Center, Department of Mathematics, Faculty of Applied Science, King Mongkut's University of Technology North Bangkok (KMUTNB), Wongsawang, Bangsue, Bangkok 10800, Thailand

E-mail: kanokwan.s@sci.kmutnb.ac.th

Abstract. In this paper, we study and consider the positive solution of fractional differential equation with nonlocal multi-point conditions of the from:

$$
\begin{aligned}
& R L D_{0^{+}}^{q} u(t)+g(t) f(t, u(t))=0, t \in(0,1) \\
& u^{(k)}(0)=0, \quad u(1)=\sum_{i=1}^{m} \beta_{i} R L D_{0^{+}}^{p_{i}} u\left(\eta_{i}\right)
\end{aligned}
$$

where $n-1<q<n, n \geq 2, n-1<p_{i}<n, q>p_{i} m, n \in \mathbb{N}, k=0,1, \cdots, n-2,0<\eta_{1}<\eta_{2}<$ $\cdots<\kappa, \beta_{i} \leq 0, \kappa \in(0,1],{ }_{R L} D_{0^{+}}^{q},{ }_{R L} D_{0^{+}}^{p_{i}}$ are the Riemann-Liouville fractional derivative of order $q, p_{i}, f:[0,1] \times C([0,1], E) \rightarrow E, E$ be Banach space and $g:(0,1) \rightarrow \mathbb{R}^{+}$are continuous functions. The main tools for finding positive solutions of the above problem are the fixed point theorems of Guo-Krasnoselskii and of Boyd and Wong. An example is included to illustrate the applicability of our results.

Key Words and Phrases: Boundary value problems, Riemann-Liouville fractional derivative, fixed point theorems.

2010 Mathematics Subject Classification: 74H10, 54H25, 47H10.

Acknowledgments. The authors thank the Center of Excellence in Theoretical and Computational Science (TaCS-CoE) for financial support. The first author was 
supported by the Rajamangala University of Technology Rattanakosin (RMUTR). Moreover, this project was partially supported by the King Mongkuts University of Technology North Bangkok, Contract no. KMUTNB-63-KNOW-033.

\section{REFERENCES}

[1] B. Ahmad, A. Alsacdi, S.K. Ntouyas, J. Tariboon, Hadamard-Type Fractional Differential Equations Inclusions and Inequalities, Springer International Publishing, 2017.

[2] A. Bakakham, V.D. Geji, Existence of positive solutions of nonlinear differential equations, J. Math. Anal. Appl., 278(2003), 434-442.

[3] D. Baleanu, S. Rezapour, Z. Saberpour, On fractional integro-differential inclusions via the extended fractional Caputo Fabrizio derivation, Boundary Value Problems, 2019, 79 (2019), https://doi.org/10.1186/s13661-019-1194-0.

[4] P. Borisut, P. Kumam, I. Ahmed, K. Sitthithakerngkiet, Nonlinear Caputo fractional derivative with nonlocal Riemann-Liouville fractional integral condition via fixed point theorems, Symmetry, 11(2019), no. 6.

[5] D. Dellbosco, Fractional calculus and function spaces, J. Fractional Calculus and Applications, 6(1996), 45-53.

[6] J. Deng, L. Ma, Existence and uniqueness of solutions of initial value problems for nonlinear fractional differential equations, Appl. Math. Letters, 23(2010), 676-680.

[7] C.A. Hollon, J.T. Neugebauer, Positive solutions of a fractional boundary value problem with a fractional derivative boundary condition, Dynamical Systems, Differential Equations and Applications, AIMS Proceedings 2015, 615-620, doi: 10.3934/proc.2015.0615.

[8] A.A. Kilbas, H.M. Srivastava, J.J. Trujillo, Theory and Applications of Fractional Differential Equations, North-Holland Mathematics Studies, vol. 204, 2006.

[9] K.S. Miller, B. Ross, Fractional calculus and fractional differential equations, J. Fractional Calculus and Applications., 3(1993), 49-57.

[10] I. Podlubny, Mathematics in Science and Engineering, Academic Press, New York, 1999.

[11] Y. Qiao, Z. Zhou, Existence of positive solutions of singular fractional differential equations with infinite-point boundary conditions, Advances in Difference Equations, 2017, 8 (2017). https://doi.org/10.1186/s13662-016-1042-9.

[12] S. Rezapour, V. Hedayati, On a Caputo fractional differential inclusion with integral boundary condition for convex-compact and nonconvex-compact valued multifunctions, Kragujevac J. Math., 41(2017), no. 1, 143-158.

[13] J. Tariboon, S.K. Ntouyas, W. Sudsutad, Nonlocal Hadamard fractional integral conditions for nonlinear Riemann-Liouville fractional differential equations, Boundary Value Problems, 2014, 253 (2014), https://doi.org/10.1186/s13661-014-0253-9

[14] X. Zhang, L. Wang, S. Qian, Existence of positive solutions for a class of nonlinear fractional differential equations with integral boundary conditions and a parameter, Appl. Math. Comp., 226(2014), 708-718.

[15] Y. Zhou, J. Wang, L. Zhang, Basic Theory of Fractional Differential Equations, World Scientific, 2013.

Received: November 11, 2019; Accepted: January 22, 2020. 
